\title{
DISLOCATION OF THE TESTIS AS A DELAYED PRESENTATION OF SCROTAL TRAUMA
}

\author{
STEPHEN L. SCHWARTZ, M.D. \\ GARY J. FAERBER, M.D.
}

From the Section of Urology, Department of Surgery, University of Michigan Medical Center, and Veteran's Affairs Medical Center, Ann Arbor, Michigan

\begin{abstract}
Traumatic dislocation of the testis is a rare event in which the full extent of the dislocation is present immediately following the initial trauma. We present a case in which the testicular dislocation progressed over a period of four days following the initial scrotal trauma.
\end{abstract}

Traumatic dislocation of the testis is a rare occurrence. ${ }^{1-9}$ The full extent of the dislocation is usually present at the time of injury. We describe a case in which progression of the testicular dislocation occurred over four days. The mechanism of injury, diagnusis, and management of traumatic testicular dislocation are reviewed.

\section{CASE REPORT}

A thirty-eight-year-old male pedestrian involved in a pedestrian-motor vehicle accident was evaluated by the trauma service at our institution for multisystem injuries, which included a closedhead injury, a right tibiofibular fracture, and abdominal and scrotal lacerations. Initial genitourinary examination revealed a $5 \mathrm{~cm}$ scrotal laceration along the median raphe down to but not through the dartos layer. The testes were reportedly both palpable within the scrotal sac without any abnormality. No other genitourinary injuries were noted.

He was taken to the operating room for treatment of his orthopedic injuries. Intraoperative urologic consultation was obtained regarding the scrotal laceration. Examination (twelve hours after the initial injury) remained essentially unchanged from that described during his initial evaluation. The scrotal wound was debrided and managed conservatively with cleansing and dressing changes.

Re-examination on the first postoperative day revealed that the right normal testis was now located more superiorly near the external ring, whereas initially it was completely dependent. The patient did well until the fourth postoperative day when

$\overline{\text { Submitted: August 4, 1993, accepted (with revisions): November }}$ 2.3. 1993 he experienced progressive pain in the right groin. Examination now revealed an empty right hemiscrotum. The right testicle was palpable below the external ring. Ultrasonography confirmed the position of the testicle high in the superficial inguinal pouch.

Surgical exploration of the right groin revealed a subcutaneous testicle deep to Scarpa's fascia but superficial to the inguinal canal. The testicle and cord were reflected obliquely over the inguinal canal with further dislocation prevented by the external inguinal ring. The tunica vaginalis appeared to be intact but the spermatic cord tunic could not be assessed with certainty. The testis was normal except for a superior inferior pole hematoma. Inversion of the scrotum revealed a hematoma at the base consistent with a gubernacular avulsion. The testis was replaced in the scrotum and orchidopexy was performed. The patient's pain resolved and he recovered without incident. Six-month follow-up examination revealed a normal testicle in a dependent position in the right hemiscrotum.

\section{COMMENT}

Serious traumatic injury to the testis seems to be a rare event. Fewer than 120 total cases of testicular rupture or dislocation have been reported in the English literature. ${ }^{9-13}$ This presumably reflects the remarkable protective mechanisms of the testis, which include its resilient tough outer capsule, its ability to be displaced within the scrotum with minimal tissue shear, and the reflex retractile capabilities of the cremasteric muscle. In a series of sixty-six blunt traumatic injuries to the testis over twenty years, 48 percent of the testes were ruptured but none was dislocated. ${ }^{12}$ 
The first case was documented by Claubry ${ }^{2}$ in 1809 and was also the first bilateral occurrence. In 1929, Alyea' delineated the possible locations of the dislocated testis and hypothesized that if the testis was freely mobile and the external ring was intact, the testis could lie anywhere along a circle with its radius being the spermatic cord and its center being the external ring. In order of frequency of occurrence, the possible areas include superficial inguinal, pubic, canalicular, penile, intra-abdominal, perineal, and crural (Fig. 1). Canalicular and intra-abdominal dislocations are almost always associated with a preexisting inguinal hernia. A variation of an intra-abdominal dislocation has been described on two occasions associated with severe pelvic fractures in which the testicle is displaced inferiorly into the acetabulum. Femoral canal dislocation, although theoretically possible, has not yet been reported.

According to Herbst and Polkey, ${ }^{3}$ the most common dislocation requires that the testis rupture through the external, cremasteric, and internal spermatic fascia leaving the tunica vaginalis and gubernaculum intact. ${ }^{3}$ If the gubernaculum is avulsed, the testis need rupture only through the external and cremasteric layers before obtaining complete range of motion. The final resting place of the testis is determined by the direction of injuring force and the path of least resistance.

Ockuly ${ }^{4}$ described testicular dislocation as a simultaneous crushing and squeezing action directed obliquely over the scrotum and inguinal region. The testis must first be displaced across the pubis. If it is caught at the level of the pubis at the time of maximum impact, testicular rupture would be the likely outcome. Once the testis is displaced over the pubic bone, the maximum impulse of the force is directed against the spermatic cord tunics and gubernaculum. If the force is inadequate to rupture the spermatic cord tunics, the testis usually will spontaneously return to its natural position. ${ }^{3}$ It is possible that successful results with early nonoperative reduction involved dislocations not associated with rupture of the spermatic cord tunics. If rupture of the spermatic cord tunics has occurred, a "button-hole" defect would make anatomic repositioning of the testis nonoperatively very difficult.

Motorcycle straddle injuries have provided the majority of cases, although a number of alternative causes have been reported ranging from kicks to the perineum to falling accidents. Associated injuries range from trivial scrotal and inguinal hematomas and lacerations to pelvic and extremity fractures and penile avulsions. Notable is that as-

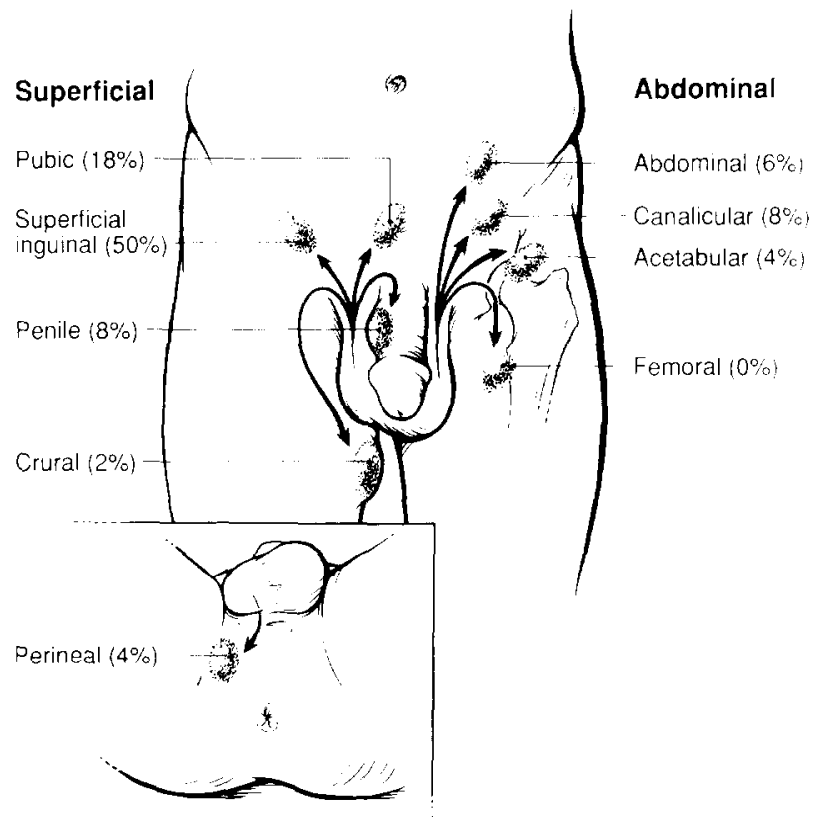

FIGURE 1. Possible sites and reported frequency of testicular dislocation.

sociated testicular injury is rare. In all cases, except one, the testis has been completely viable. Epididymal avulsion has also rarely been associated with testicular dislocation. ${ }^{5}$

All cases to date, however, document the full extent of the dislocation immediately at the time of injury. Diagnosis has been delayed in some cases due to the presence of a scrotal hematoma, but no case has documented the displacement occurring over a prolonged time period. In our case, the testis was freely mobilized at the time of the initial injury but the testicular displacement to its final resting place occurred over several days. We theorize that in our case the initial force of the injury resulted in the avulsion of the gubernaculum, but a secondary force resulted in the delayed dislocation. This force was a combination of gravity with the patient in the supine position combined with the scrotal dressing changes. The cause of the sudden discomfort is less clear and could represent local pressure effects or torsion.

Surgical reduction and fixation are the treatments of choice for patients with testicular dislocation. Although closed reduction has been advocated by some, the force needed to reposition the testis could theoretically produce further insult. The addition of ultrasound, especially with color Doppler, may allow for more accurate preoperative staging. ${ }^{14}$ If the testis can be adequately imaged so as to ensure its tunical integrity and symmetric blood flow relative to the contralateral testis, a trial of closed reduction may be reasonable. Nonoperative 
attempts, in our opinion, if used at all, are best reserved for cases associated with minimal trauma in which the affected testicle is easily reduced and there is a normal contralateral testis. We recommend scrotal repositioning in all cases to facilitate testicular examination. Early operative reduction and fixation provide for certain testicular positioning without risking further injury. ${ }^{15}$ Given the limited morbidity of operative exploration, early surgical reduction with confirmation of testicular integrity is recommended.

Gary J. Faerber, M.D. University of Michigan Medical Center Section of Urology, TC 2918 1500 East Medical Center Drive Ann Arbor, Michigan 48109-0330

\section{REFERENCES}

1. Alyea EP: Dislocation of testis. Surg Gynecol Obstet 49: 600-616, 1929.

2. Claubry E: Observation sur une retrocession subite des deux testicules dans l'abdomen, à la suite d'une violente compression de la partie inferieure de la paroi abdominale par une roue de charrette. J Gen Med Chir Pharmacol 64: 325 , 1818.

3. Herbst RH, and Polkey HJ: Luxatio testis traumatica and experimental study of mechanism. Am I Surg 34: 18-33, 1936

4. Ockuly EA: Traumatic luxation of the testis. Am J Surg 71: 93-95, 1946

5. Edson M, and Meek JM: Bilateral testicular dislocation with unilateral rupture. J Urol 122: 419-420, 1979.

6. Morgan A: Traumatic luxation of the testis. Br J Surg 52: $669-672,1965$.

7. Singer AJ, Das $S$, and Gavrell GJ: Traumatic dislocation of the testes. Urology 35: 310-312, 1990.

8. Nagarajan VP, Pranikoff $\mathrm{K}$, Imahori SC, and Rabinowitz R: Traumatic dislocation of testis. Urology 22: 521-524, 1983.

9. Warden S, and Schellhammer PF: Bilateral testicular rupture: report of a case with an unusual presentation. I Urol 120: 257-258, 1978.

10. Atwell JP, and Ellis H: Rupture of the testis. Br J Surg 49: 345-346, 1961

l I. McAninch JW, Kahn RI, Jeffrey RB, I aing FC, and Krieger MJ: Major traumatic and septic genital injuries. J Trauma 24: 291-298, 1984.

12. Cass AS: Testicular trauma. J Urol 129: 299-300, 1983.

13. Gopinatha K: Traumatic rupture of testis. Urology 20 : $624-625,1982$

14. Horstman WG, Middleton WD, Melson Gl, and Siegel BA: Color Doppler US of the scrotum. Radiographics 11: 941-958, 1991

15. Del Villar RG, Ireland GW, and Cass AS: Early cxploration following trauma to the testicle: Trauma 13 . $600-601,1973$ 